\title{
Guidelines for Distribution System Operators on Reactive Power Provision by Electric Vehicles in Low Voltage Grids
}

\author{
Zecchino, Antonio; Marinelli, Mattia; Træholt, Chresten; Korpås, Magnus
}

Published in:

Cired - Open Access Proceedings Journal

Link to article, DOI:

10.1049/oap-cired.2017.0377

Publication date:

2017

Document Version

Publisher's PDF, also known as Version of record

Link back to DTU Orbit

Citation (APA):

Zecchino, A., Marinelli, M., Træholt, C., \& Korpås, M. (2017). Guidelines for Distribution System Operators on Reactive Power Provision by Electric Vehicles in Low Voltage Grids. Cired - Open Access Proceedings Journal, 2017(1), 1787 - 1791. https://doi.org/10.1049/oap-cired.2017.0377

\section{General rights}

Copyright and moral rights for the publications made accessible in the public portal are retained by the authors and/or other copyright owners and it is a condition of accessing publications that users recognise and abide by the legal requirements associated with these rights.

- Users may download and print one copy of any publication from the public portal for the purpose of private study or research.

- You may not further distribute the material or use it for any profit-making activity or commercial gain

- You may freely distribute the URL identifying the publication in the public portal 


\section{GUIDELINES FOR DISTRIBUTION SYSTEM OPERATORS ON REACTIVE POWER PROVISION BY ELECTRIC VEHICLES IN LOW VOLTAGE GRIDS}

\author{
Antonio ZECCHINO, Mattia MARINELLI, \\ Chresten TRÆHOLT \\ Technical University of Denmark - Denmark \\ \{antozec, matm, ctr\}@elektro.dtu.dk
}

\author{
Magnus KORPÅS \\ Norwegian University of Science and Technology - Norway \\ magnus.korpas@ntnu.no
}

\begin{abstract}
The increasing success of electric vehicles is bringing new technical challenges to power system operators. This work intends to provide guidelines for distribution system operators in terms of reactive power requirements when evaluating and authorizing electric vehicles supply equipment with fast charging capability in existing low voltage distribution feeders. The aim is to prevent the voltage to exceed the permitted values when charging at high power, by exploiting the effect of the reactive power. The proposed guidelines for distribution system operators are reported in a matrix, which indicates the amount of reactive power that an individual electric vehicle is expected to provide when connected to a low voltage feeder, in order to benefit of the desired voltage rise effect in comparison to the case of unitary power factor.
\end{abstract}

\section{INTRODUCTION}

The growing penetration of electric vehicles (EVs) brings new challenges to power system operators. Great research effort is made in smart integration solutions of large amount of EVs in the power system, e.g., smart charging according to market price signals or relying on specific control logics with the aim of making EVs a reliable source of system-wide ancillary services [1], [2]. Within this context, to validate the feasibility of the proposed solutions, the technical capabilities of series-produced EVs in performing smart charging are of high interest [3]. One of the most challenging aspects of the integration of EVs in the power system is their impact on distribution grids [4]. In fact, when connected to electric vehicles supply equipment (EVSE), they behave as large concentrated loads, that may cause technical issues on the electrical infrastructure. Overloading conditions may arise both in distribution transformers and feeders and the power quality may drastically worsen, which is supposed to be assured at standard-compliant levels by distributor system operators (DSOs).

For this reason, many studies have been conducted with the aim to demonstrate the potentials of distributed control for EV charging to solve local voltage issues and allowing high EV penetration to be technically acceptable without the need of investment in additional units for grid reinforcement [4].

In general, voltage support by reactive power provision is seen as one of the most effective solutions to solve local voltage issues in distribution networks [5]. Similarly to the case of small distributed generation plants connected at low voltage levels [6], [7], it is expected that there might by a need for DSOs to require voltage support capability also to the new EVSEs [8], [9].

In this context, for installations of new commercial EVSEs with fast charging capability in existing low voltage (LV) distribution feeders, a certain amount of reactive power needs to be available in order to prevent undesired under-voltages. This work focuses on the potential of reactive power in distribution networks, and provides guidelines for DSOs in a matrix, which indicates the amount of reactive power that an individual EV must be able to provide when charging at high power connected at a LV level. Specifically, the proposed analysis demonstrates that both the MV/LV transformer and the MV grid (unless extremely weak) have marginal influence on the effects of reactive power on the voltage. Moreover, it is also found that the $\mathrm{R} / \mathrm{X}$ ratio of the $\mathrm{LV}$ feeder does not significantly influence the results, whereas a meaningful comparison is instead the absolute values of $\mathrm{R}$ and $\mathrm{X}$, i.e., the $\mathrm{LV}$ feeder length.

An analytical formulation is proposed and an analysis has been carried out by implementing the equations in MATLAB, The MathWorks, Inc. For a further validation, load flow calculations in the power system simulation tool DIgSILENT PowerFactory have been run.

\section{ELECTRIC VEHICLES AS SUPPORT FOR DITRIBURION NETWORKS}

In general, DSOs should be always able to operate their distribution networks assuring standard-compliant levels of power quality. The increasing penetration of small distributed energy resources is making the operation more challenging. For example, unless opting for expensive investments in grid reinforcement, a massive penetration of EVs in distribution networks will force DSOs relying on third party service solutions by smart EV charging.

One of the most straightforward ways of identifying distribution grid services is to associate them with the DSO's needs of optimally operating the grid. Accordingly, correspondent EV charging strategies should be defined depending on the objective set for a particular grid service. The EV charging objectives can 
be either technical, economic or a combination of both. Aiming at achieving technical objectives, the services can generally be divided in two groups depending on the targeted grid constraint, namely services for solving loading issues and services for solving voltage issues. The first group can be further divided into two subgroups, i.e., congestion prevention and loss reduction. Voltage issues can be solved by regulating the voltage magnitude or by reducing phase-unbalances caused by single-phase connected units.

In this work, the voltage magnitude regulation is investigated. In particular, the use of reactive power for voltage support is analysed. Reactive power can be seen both as a traded flexibility service that the EV owner can offer to the DSO, or it can be seen as an implicit EV charging characteristic. In the latter case, it would be seen as a mere technical capability both for the EV and the EVSE. Within this context, this work highlights the effective contribution of reactive power to local voltage support by EVs connected to typical LV feeders.

\section{REACTIVE POWER MANAGEMENT IN DISTRIBUTION NETWORKS}

Local voltage support by reactive power provision is seen as one of the most effective solutions to solve local voltage issues in distribution networks. As low voltage distribution grids are typically characterized by average $\mathrm{R} / \mathrm{X}$ ratio of $0.5-5$, the reactive power has significant effects on the voltage [8], [9].

For residential photovoltaic installations connected to distribution grids voltage regulation by reactive power provision is already required in most of the European countries, where national grid codes require reactive power management. [6], [7]. Similarly, the EV charging process could be performed utilizing a capacitive power factor, i.e., injecting reactive power, with the aim at avoiding under-voltage conditions.

In distribution grids the transversal parameters conductance and susceptance are negligible for LV levels. All the grids with negligible transversal parameters can be represented by an R-L circuit as the one in Fig.1, which shows the single-phase equivalent circuit of a three-phase line, where $R_{1}$ and $X_{1}$ are the longitudinal parameters of the distribution line, $\overline{\mathrm{E}_{1}}$ and $\overline{\mathrm{E}_{2}}$ the phase-neutral voltages at the two terminals, and $\overline{\Delta E}$ the voltage drop along the line.

As it can be seen in the phasor diagram in Fig. $2-a, \overline{E_{2}}$ is considered as reference, and therefore $\overline{\mathrm{E}_{1}}$ and $\bar{I}$ are shifted by $\varepsilon$ and $\varphi$, respectively. Note that the sign of the real component of the current $I_{r}$ indicates whether the EV is

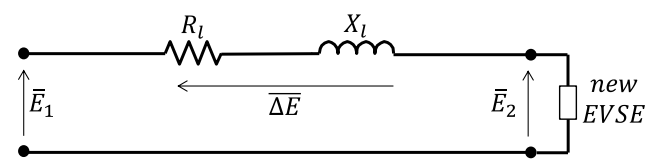

Fig. 1. Single-phase equivalent circuit of a three-phase LV line.

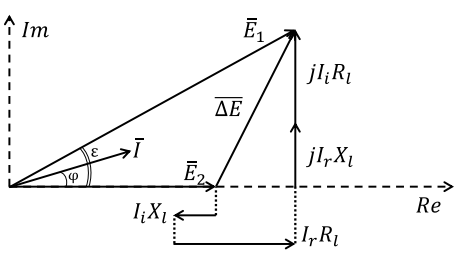

(a)

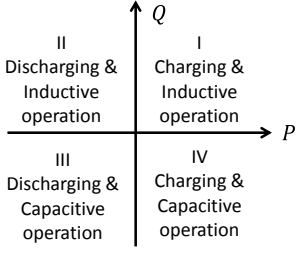

(b)
Fig. 2. a: vector diagram. b: 4-quadrant EVSE converter operating scheme.

charging or discharging, corresponding to the I/IV or II/III quadrants of the P-Q 4-quadrant EVSE converter operating scheme of Fig. 2-b. The phase angle $\varphi$ and therefore the imaginary component $\mathrm{I}_{\mathrm{i}}$, shows if it is exchanging inductive or capacitive reactive power (I/II or III/IV quadrant).

As it can be deduced by the phasor diagram and by the general Eq. (1), by considering $\mathrm{I}_{\mathrm{r}}$ and $\mathrm{I}_{\mathrm{i}}$, it is possible to notice how they influence the voltage magnitude $\left|\overline{E_{2}}\right|$, due to the impedance of the line $\left(\mathrm{R}_{1}+\mathrm{j} \mathrm{X}_{1}\right)$.

$\left|\overline{E_{2}}\right|=\sqrt{\left|\overline{E_{1}}\right|^{2}-\left|I_{i} R_{l}+I_{r} X_{l}\right|^{2}}-\left|I_{r} R_{l}\right|+\left|I_{i} X_{l}\right|$

It is clear that the voltage drop due to active current absorption $-\mathrm{I}_{\mathrm{r}} \mathrm{R}_{1}$ is partially compensated by the voltage rise due to the reactive current $+\mathrm{I}_{\mathrm{i}} \mathrm{X}_{1}$. Thus, in order to support the grid during EV charging, instead of reducing the active charging power and thereby impacting the user comfort, injecting capacitive reactive power can be seen as an attractive alternative, thus operating in the IV quadrant of the EVSE converter charging capabilities in Fig. 2-a.

The main purpose of the proposed analysis is to provide guidelines for DSOs in terms of reactive power provision requirement for new EVSEs installation. Therefore, the determination of the effect of reactive power on the voltage at the end of the line as function of the installed apparent power is of high importance. Eq. (1) has been re-formulated in Eq. (2), which highlights separately the active power $\mathrm{P}$ and the reactive power $\mathrm{Q}$. In this way it is possible to calculate the voltage magnitude at the end terminal of a line $\left|\overline{\mathrm{E}_{2}}\right|$, given the line parameters, the voltage at the source terminal, and the EV charging power, in terms of $\mathrm{P}$ and $\mathrm{Q}$, i.e., in terms of $\mathrm{P}$ and power factor $\cos (\varphi)$.

$\left|\overline{E_{2}}\right|=\sqrt{\frac{1}{2}\left[\left|\overline{E_{1}}\right|^{2}+\frac{2}{3}\left(-P R_{l}+Q X_{l}\right)+\sqrt{\left|\overline{E_{1}}\right|^{4}+\frac{4}{3}\left|\overline{E_{1}}\right|^{2}\left(-P R_{l}+Q X_{l}\right)-\frac{4}{9}\left(Q R_{l}+P X_{l}\right)^{2}}\right]}$

\section{METHODOLOGICAL APPROACH}

The first part of the investigation aims at evaluating the influence of the MV grid, the MV/LV transformer, and the LV feeder on the effects of reactive power on voltage support. In order to do that, the single-line equivalent circuit in Fig. 3-a was considered, which has been schematized by considering the equivalent single-phase circuit with all the parameters referred to the $0.4 \mathrm{kV} \mathrm{LV}$ 
level, reported in Fig. 3-b. In the proposed model no other loads are considered in the analysis. Specifically, if the voltage raises a constant-power load would draw less current, thus enhancing the voltage regulation effect determined by reactive power provision. On the other hand, a constant-impedance load would consume more, thus reducing the effectiveness.

Fig. 3-b shows the resistive and inductive components referred to the LV level of MV grid, MV/LV transformer, and $L V$ feeder. These are termed $\mathrm{R}_{\mathrm{MVgrid}}$ and $\mathrm{X}_{\mathrm{MVgrid}}$, $\mathrm{R}_{\text {trafo }}$ and $\mathrm{X}_{\text {trafo }}$, and $\mathrm{R}_{\mathrm{LVfeeder}}$ and $\mathrm{X}_{\mathrm{LVfeeder}}$, respectively. Referring to the analysis in the previous Section, the series of the three resistive and inductive components correspond to $R_{1}$ and $X_{1}$ of Fig. 1 and Eq. (1) and (2).

Eq. (2) has been implemented, and $\left|\overline{E_{1}}\right|$ set to 1 p.u. as for an ideal voltage source. Anyway, the aim of the study is assessing the voltage difference, thus the findings are still applicable also in other situations (i.e., higher voltages such as 1.05 because of reverse flow, or lower voltages such as 0.95 because of loaded feeders).

Typically, the $10 \mathrm{kV}$ MV grid's characteristics are represented by the short-circuit power $\mathrm{S}_{\mathrm{sc} \_ \text {MVgrid }}$ and the $\mathrm{R} / \mathrm{X}_{\text {MVgrid }}$ ratio. Taking the MV equivalent network of European LV distribution network proposed by Cigrè [10], typical values are 10 MVA and 0.5, respectively. Through calculation of the short-circuit impedance, the resistive and inductive components referred to the $\mathrm{LV}$ level $\mathrm{R}_{\mathrm{MVgrid}}$ and $\mathrm{X}_{\mathrm{MVgrid}}$ amount to $0.00716 \Omega$ and $0.01431 \Omega$, respectively.

A typical $\mathrm{MV} / \mathrm{LV}$ distribution power transformer has been modelled [3]. It is characterized by nominal apparent power $\mathrm{S}_{\mathrm{n}_{-} \text {trafo }}$ of $0.4 \mathrm{MVA}$, short-circuit voltage $\mathrm{V}_{\mathrm{sc} \% \text { trafo }}$ of $4 \%$, and $\mathrm{R} / \mathrm{X}_{-}$trafo ratio of $0.1 . \mathrm{R}_{\text {trafo }}$ and $\mathrm{X}_{\text {trafo }}$ amount to $0.00159 \Omega$ and $0.0159 \Omega$, respectively.

As proposed by Cigrè [10], typical values of the cable resistance and reactance per $\mathrm{km}$ are 0.163 and 0.136 $\Omega / \mathrm{km}$, respectively ( $\mathrm{R} / \mathrm{X}_{\text {LVfeeder }}$ ratio of 1.2$)$. A length of $1 \mathrm{~km}$ has been chosen, as it is indicated as a typical length for $\mathrm{LV}$ feeders in [11]. Therefore, $\mathrm{R}_{\mathrm{LVfeeder}}$ and $\mathrm{X}_{\mathrm{LVfeeder}}$ amount to $0.163 \Omega$ and $0.136 \Omega$, respectively.

Table 1 reports the considered typical values of power system components when modelling LV distribution grids. It also includes the related equivalent resistance and reactance referred to the LV level, with reference to the simplified single-phase equivalent circuit in Fig. 3-b.

Considering installation of new EVSEs with fast-

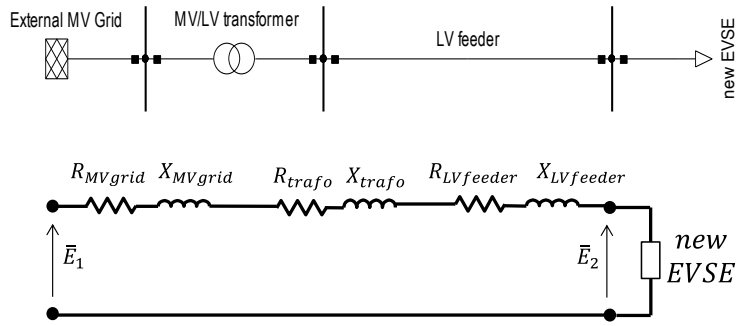

Fig. 3. Single-phase equivalent circuit of the threephase power system under exam. charging capability up to $12 \mathrm{~kW}$, it has been decided to assume a total EV active power demand of $50 \mathrm{~kW}$, which represent a realistic case of 4 new EVSEs.

In order to evaluate the voltage rise due to reactive power, Eq. (2) has been implemented with power factor $\cos (\varphi)$ equal to 1 and then repeated with capacitive $\cos (\varphi)$ equal to 0.9 , and the difference $\Delta \mathrm{E}_{2}$ was evaluated.

Table 1 - Standard parameters for distribution grids

\begin{tabular}{|c|c|c|c|c|c|c|}
\hline & $\begin{array}{c}\mathrm{S}_{\text {sc_Mggrid }} \\
{[\mathrm{MVA}]}\end{array}$ & $\begin{array}{c}\mathrm{S}_{\mathrm{n}} \text { trafo } \\
{[\mathrm{MVA}]}\end{array}$ & $\begin{array}{c}\mathrm{V}_{\text {sc\% }} \text {-trafo } \\
{[\%]}\end{array}$ & $\mathrm{R} / \mathrm{X}$ & $\begin{array}{c}\mathrm{R} \text { referred to } \\
\text { LV level }[\Omega]\end{array}$ & $\begin{array}{c}\mathrm{X} \text { referred to } \\
\text { LV level }[\Omega]\end{array}$ \\
\hline $\begin{array}{c}\mathrm{MV} \\
\text { grid }\end{array}$ & 10 & - & - & 0.5 & 0.00716 & 0.01431 \\
\hline $\begin{array}{c}\mathrm{MV} / \mathrm{LV} \\
\text { trafo }\end{array}$ & - & 0.4 & 4 & 0.1 & 0.00159 & 0.0159 \\
\hline $\begin{array}{c}\mathrm{LV} \\
\text { feeder }\end{array}$ & - & - & - & 1.2 & 0.163 & 0.136 \\
\hline
\end{tabular}

Considering the calculated constant values of the series resistive and reactive components of the circuit in Fig. 3$\mathrm{b}$, a preliminary analysis of the influence of the three single components on the effects of reactive power is now presented. In case of unitary and capacitive power factor equal to $0.9, \mathrm{E}_{2}$ resulted in 0.9673 and 0.9415 p.u., respectively. It is clear that the difference $\Delta \mathrm{E}_{2}(0.0258$ p.u.) represents the voltage rise due to the reactive power injected by the EVs at the ending terminal of the line. The resulting $\Delta \mathrm{E}_{2}$ is obtained from all the three modelled components. Specifically, the MV grid contributed $8.5 \%$, the transformer $9.4 \%$, while the LV feeder contributed $82.1 \%$, as illustrated schematically in Fig. 4.

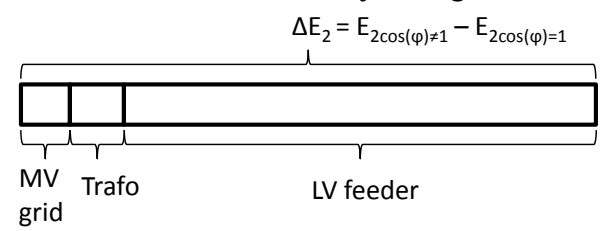

Fig. 4. Contribution to the reactive power effect on the voltage at the end of the line for each component.

It is therefore found that the effect of the reactive power on the local voltage depends mainly on the characteristics of the LV feeder. This result was obtained considering one possible combination of typical distribution network components. Thus, it is of interest to see how different values of these components may impact the result. In this regards, the next part of the investigation aims at evaluating the influence of the MV grid, the MV/LV transformer, and the LV feeder parameters on the effects of reactive power on the voltage.

\section{Influence of the MV grid}

The influence of the external MV grid was evaluated by calculating $\Delta \mathrm{E}_{2}$ first for different short-circuit powers $\mathrm{S}_{\text {sc_MVgrid }}$ (1-10 MVA) and then for different $\mathrm{R} / \mathrm{X}_{\text {_MVgrid }}$ (0.05-0.5), keeping constant the typical parameters of transformer and LV feeder of Table 1.

Fig. 5-a shows that the trend of $\Delta \mathrm{E}_{2}$ is influenced by the stiffness of the external MV grid, keeping, as in [10], the constant value of 0.5 for $\mathrm{R} / \mathrm{X}_{\text {MVgrid. }}$ In particular, it is found that for very weak grids, results differ from the 


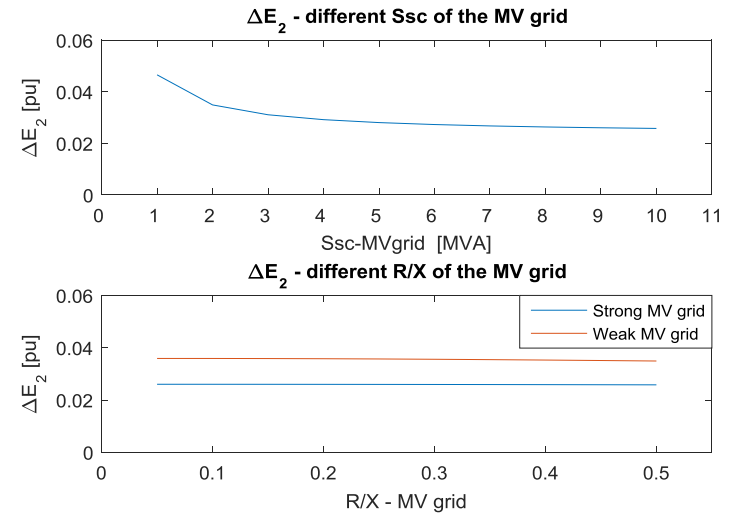

(a)

\section{Fig. 5. Influence of MV grid.}

case of strong ones. Therefore, it was decided to carry out all the studies hereafter by considering always the comparison of two kinds of $\mathrm{MV}$ grid: a weak grid $\left(\mathrm{S}_{\mathrm{sc} \_ \text {MVgrid }}=2 \mathrm{MVA}\right)$ and a strong grid $\left(\mathrm{S}_{\mathrm{sc} \_ \text {MVgrid }}=10 \mathrm{MVA}\right)$. Fig. 5-b shows that, for both the compared MV grids, the effect of reactive power on the ending terminal voltage is constant for all the considered $\mathrm{R} / \mathrm{X}_{\mathrm{MVgrid}}$ ratios. For this reason, hereafter the constant value of 0.5 for $\mathrm{R}^{-} \mathrm{X}_{-} \mathrm{MV}$ grid was used.

\section{Influence of the distribution MV/LV transformer}

The influence of the distribution MV/LV transformer has been evaluated by calculating $\Delta \mathrm{E}_{2}$ for different nominal apparent powers $S_{n \text { trafo }}$ (0.1-1 MVA), keeping constant the typical parameters of $\mathrm{v}_{\mathrm{sc}_{\text {_t }} \text { trafo }}, \mathrm{R} / \mathrm{X}_{\text {_trafo }}$ and $\mathrm{LV}$ feeder reported in Table 1. As motivated before, the analysis is done both for weak and strong MV grid.

Fig. 6 shows that the influence of the distribution transformer on the effect of reactive power is marginal for $\mathrm{S}_{\mathrm{n}_{-} \text {trafo }} \geq 0.2 \mathrm{MVA}$, while for very small sizes $\left(\mathrm{S}_{\mathrm{n}_{-} \text {trafo }}\right.$ $<0.2$ MVA), the contribution becomes noticeable. As the grid model considers a LV feeder at the secondary side of the transformer, it is to be expected that in addition to the new EVSEs at the line end, distributed loads may be connected along the feeder. Thus, as in this study a realistic case of new EVSEs installation for a total of 50 $\mathrm{kW}$ is considered, a minimum size of $0.2 \mathrm{MVA}$ is to be considered for the transformer.

For this reason, hereafter the typical values of the $\mathrm{MV} / \mathrm{LV}$ transformer reported in Table 1 have been considered and kept constant, as its influence on the effect of the reactive power is considered marginal.

\section{Influence of the $L V$ feeder}

The influence of the LV feeder has been evaluated by calculating $\Delta \mathrm{E}_{2}$ first for different $\mathrm{R} / \mathrm{X}_{-} \mathrm{LVfeeder}$ and then for

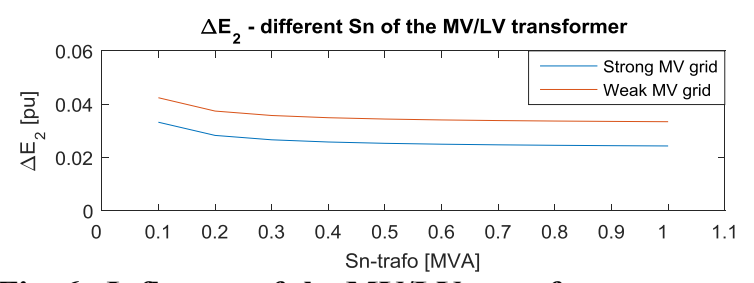

Fig. 6. Influence of the MV/LV transformer.
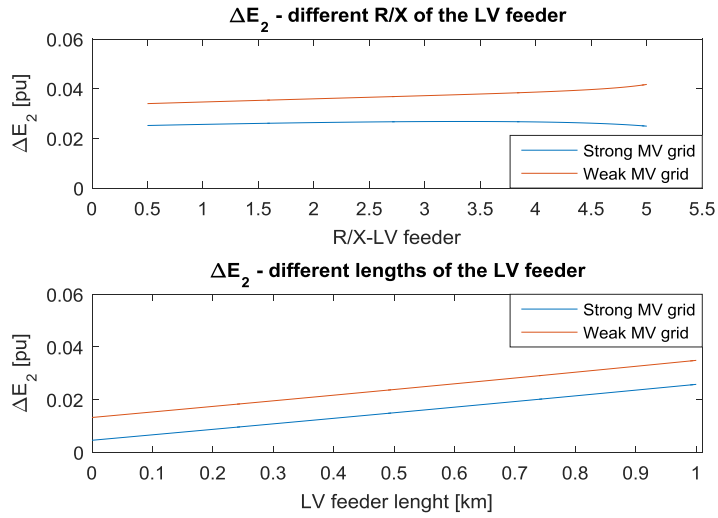

(b)

Fig. 7. Influence of the $\mathrm{LV}$ feeder

different lengths, considering both weak and strong MV grid, and the MV/LV transformer from Table 1.

Since it is known that the reactance per $\mathrm{km}$ is usually constant for different kinds of cables, for the first case different $\mathrm{R} / \mathrm{X}_{\text {LVfeeder }}$ have been obtained by varying the value of the resistive component $(0.07-0.7 \Omega / \mathrm{km})$, i.e., by considering different sections of the cable conductors, keeping the length equal to $1 \mathrm{~km}$ [11]. For the case of different lengths $(0-1 \mathrm{~km})$, the values per $\mathrm{km}$ reported in Table 1 were used and kept constant.

Fig. 7-a shows that for different $\mathrm{R} / \mathrm{X}_{-} \mathrm{LVfeeder}, \Delta \mathrm{E}_{2}$ results relatively constant, while from Fig. 7 -b it is possible to deduce that the main influence is given by the absolute values of $\mathrm{R}_{\mathrm{LVfeeder}}$ and $\mathrm{X}_{\mathrm{LVfeeder}}$, i.e., by the length.

\section{Voltage rise as function of $\cos (\varphi)$ and length}

As demonstrated, the main influence on the voltage from reactive power provided by charging EVs is determined by the absolute values of the LV feeder impedance. Furthermore, it is clear that $\Delta \mathrm{E}_{2}$ depends on the amount of the capacitive reactive power provided by the EV, i.e., on the power factor $\cos (\varphi)$ set by the EVSE. For these reasons, with reference to Eq. (2), the last formulation proposed in this work considers $\Delta \mathrm{E}_{2}$ as function of the LV feeder length (varied again between 0 and $1 \mathrm{~km}$ ) and the $\cos (\varphi)$, varied between 0.9 and 1 .

Fig. 8 reports the results of the analysis by means of a 3D plot for the calculated $\Delta \mathrm{E}_{2}$ in case of both weak MV grid (top surface) and strong MV grid (bottom surface).

Table 2 presents numerical results for the case of the strong MV grid, i.e., the most common one.

Table $2-\Delta E_{2}$ for different $\cos (\varphi) /$ length combinations

\begin{tabular}{|c|c|c|c|c|c|c|c|}
\hline & \multicolumn{6}{|c|}{$\cos (\varphi)$} \\
\hline & & 1 & 0.98 & 0.96 & 0.94 & 0.92 & 0.9 \\
\hline \multirow{5}{*}{$\begin{array}{c}\text { Length } \\
{[\mathrm{km}]}\end{array}$} & 0.2 & 0 & 0.0037 & 0.0053 & 0.0066 & 0.0077 & 0.0087 \\
\hline & 0.4 & 0 & 0.0055 & 0.0078 & 0.0097 & 0.0114 & 0.0129 \\
\hline & 0.6 & 0 & 0.0073 & 0.0104 & 0.0129 & 0.0151 & 0.0171 \\
\hline & 0.8 & 0 & 0.0092 & 0.0131 & 0.0162 & 0.0189 & 0.0214 \\
\hline & 1.0 & 0 & 0.0111 & 0.0158 & 0.0195 & 0.0228 & 0.0258 \\
\hline
\end{tabular}

As expected, the effectiveness of the reactive power on the voltage support is increasing with decreasing power factor, up to the maximum value of 0.0258 p.u. for standard LV feeder length of $1 \mathrm{~km}$, for strong MV grid. Moreover, it is noticeable that for any given $\cos (\varphi)$ 


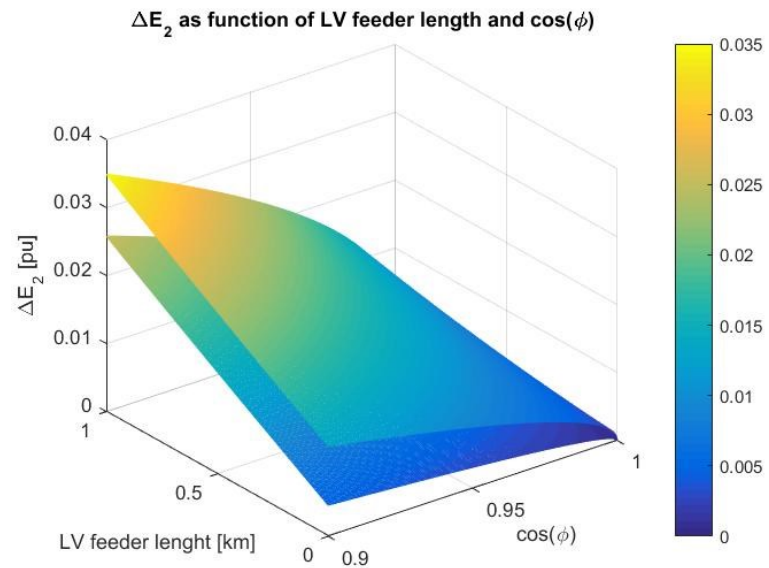

Fig. 8. Voltage rise effect of the reactive power provided by EVs as function of the $\mathrm{LV}$ feeder length.

provided by the EV charging, the effects are linearly dependent on the absolute value of the LV feeder impedance, as previously reported in Fig. 7-b for the case of $\cos (\varphi)$ of 0.9 .

\section{CONCLUSIONS AND FUTURE WORKS}

Due to expected self-induced under-voltage conditions caused by the EV charging, new fast charging EVSEs may be reluctantly allowed by the local grid operator. In order to permit installation without the need of expensive grid reinforcement, capacitive reactive power is an effective mean to reduce under-voltages. The aim of the proposed work was to analyse the potentials of reactive power provision by EVs on voltage support, depending on the grid characteristics.

A simplified distribution grid layout was considered, composed by an external MV grid, a MV/LV distribution transformer, and a single radial LV feeder. Considering multiple values of the parameters of the modelled components, it was found that the effect of the capacitive reactive power is influenced only by the stiffness of the external MV grid and by the absolute values of the LV feeder impedance. Specifically, it was found that the R/X ratio of the LV feeder did not significantly influence the results, while its absolute impedance was crucial. Since the LV cable reactance per $\mathrm{km}$ is substantially constant for most cross sections, the variety of the absolute values was obtained by considering different cable lengths.

In conclusion, the main outcome of the paper is the numerical assessment of the voltage rise due to the application of a particular power factor by the fast charger while charging, given as input the EVSE installed power and the LV feeder length. In this way, DSOs can clearly evaluate the effect of the reactive power for any of their LV feeders when the power absorbed by EVs chargers would cause unacceptable under-voltages.

It is important to state that injecting reactive power might have different effects depending on the load distribution and its nature. In fact, in case of constant-power loads, raising the voltage means reducing the active part of the current, while in case of constant-impedance loads, the consumption would increase, with the risk of experiencing overloading conditions or of increased grid losses. For this reason, the authors recognize that, case by case, additional analyses are needed to evaluate the potential drawbacks of such a solution. The proposed method is to be seen as a preliminary measure for DSOs when evaluating new EVSE installations.

Future work should cover the complete analysis of the problem, modelling a realistic and more complex distribution grid. In fact the effect on cable/transformer loading and line losses of unbalanced loads along with their voltage dependency need to be investigated.

\section{REFERENCES}

[1] S. Izadkhast, P. Garcia-Gonzalez, and P. Frias, 2015, "An Aggregate Model of Plug-In Electric Vehicles for Primary Frequency Control," IEEE Transactions on Power Systems, vol. 30, no. 3, 1475-1482.

[2] A. Zecchino, M. Rezkalla, and M. Marinelli, 2016, "Grid Frequency Support by Single-Phase Electric Vehicles: Fast Primary Control Enhanced by a Stabilizer Algorithm," in 2016 Universities Power Engineering Conference (UPEC), 1-6.

[3] K. Knezović, S. Martinenas, P. B. Andersen, A. Zecchino, and M. Marinelli, "Enhancing the Role of Electric Vehicles in the Power Grid: Field Validation of Multiple Ancillary Services," IEEE Transactions on Transportation Electrification, vol. 99, 1-9.

[4] K. Clement-Nyns, E. Haesen, and J. Driesen, 2011, "The impact of vehicle-to-grid on the distribution grid," Electric Power Systems Research, vol. 81, no. 1, 185-192.

[5] A. Kechroud, P. F. Ribeiro, and W. L. Kling, 2014, "Distributed generation support for voltage regulation: An adaptive approach," Electric Power Systems Research, vol. 107, 213-220.

[6] "Italian Technical Standard CEI 0-21", 2012.

[7] "German Technical Standard VDE-AR-N 4105", 2011.

[8] K. Knezović and M. Marinelli, 2016, "Phase-wise enhanced voltage support from electric vehicles in a Danish low-voltage distribution grid," vol. 140, 274-283.

[9] N. Leemput, F. Geth, J. Van Roy, J. Büscher, and J. Driesen, 2015, "Reactive power support in residential LV distribution grids through electric vehicle charging," Sustainable Energy, Grids and Networks, vol. 3, 24-35.

[10] K. Strunz, 2009 "CIGRE Task Force C6.04.02 Benchmark Systems for Network Integration of Renewable and Distributed Energy Resources,".

[11] L. Felix, K. Serdar, R. S. Raul, 2014, "COTEVOSSpecification of reference electricity networks," . 